\title{
Field Verification of Low-Level Biochar Applications as Effective Ameliorants to Mitigate Cadmium Accumulation into Brassica Campestris L from Polluted Farmland Soil
}

\author{
Youchi Zhang ( $\nabla$ yczhang@iue.ac.cn ) \\ Institute of Urban Environment Chinese Academy of Sciences \\ Yanwei Hou \\ Huaqiao University \\ Jiajun Fan \\ Institute of Urban Environment Chinese Academy of Sciences \\ Shanna Lin \\ Institute of Urban Environment Chinese Academy of Sciences \\ Brian J. Reid \\ University of East Anglia \\ Frédéric Coulon \\ Cranfield University \\ Chao Cai \\ Institute of Urban Environment Chinese Academy of Sciences
}

\section{Research Article}

Keywords: Biochar, Cadmium, Field application, Farmland, Brassica

Posted Date: June 3rd, 2021

DOl: https://doi.org/10.21203/rs.3.rs-487733/v1

License: (c) (i) This work is licensed under a Creative Commons Attribution 4.0 International License. Read Full License

Version of Record: A version of this preprint was published at Frontiers in Environmental Science on January 16th, 2023. See the published version at https://doi.org/10.3389/fenvs.2022.1114335. 


\section{Abstract}

Farmland soils in China have been reported to be diffusely contaminated, $\mathrm{Cd}$ has been recognized as a significant contributor to this issue and biochars have been reported to be effective in mitigating soil Cd pollution. However, previous studies have shown contradictory outcomes. Furthermore, in general, laboratory experiments and unrealistically large amounts of biochar ( $>10 t / h a)$ have been used. In this study, three biochars: rice straw biochar (RS), pig manure biochar (PM) and rice husk biochar (RH) were produced from readily available farm residues and characterized. These were used in a field experiment, at low applications rates of 1.8 and $3.6 \mathrm{t} / \mathrm{ha}$, with rape (Brassica campestris L.). Batch adsorption experiments indicated $\mathrm{Cd}$ adsorption in the order $\mathrm{RS}$ biochar $>\mathrm{PM}$ biochar $>\mathrm{RH}$ biochar. Field experiment indicated biochar amendments to slightly changes in soil $\mathrm{pH}$ and $\mathrm{CEC}$; yet led to considerable and significant decreases in extractable Cd concentrations (reductions of: $43 \%-51 \%$ (PM), $29 \%-35 \%$ (RS) and 17\%-19\% (RH)). Reduced extractable Cd correlated with lower Cd concentrations in rape plants. PM and RS biochars were the most effective in decreasing Cd phytoaccumulation into edible parts of rape ( $>68 \%$ reduction). It is highlighted that biochars were produced using a pyrolysis unit with an output of 20 ton/yr. Thus, assuming a working application rate of 2 ton/ha, the pyrolysis unit could service $10 \mathrm{ha} / \mathrm{yr}$. While at a modest scale, this research demonstrates the genuine reality of biochar-based remediation solutions to contribute to the mitigation of diffuse Cd contamination in some of China's impaired farmland.

\section{Highlights}

- Biochar-based amelioration to the mitigation diffuse Cd contamination in farmland

- Pig manure (PM) and rice straw (RS) biochar amendment resulted in lower Cd concentrations in rape

- Rice husk (RH) biochar was less effective in lowering Cd concentrations in rape plants

- Low application rates, $1.8 \mathrm{t}$ /ha of PM and RS, efficiently immobilized $\mathrm{Cd}$ in soil

- Doubling field application rates of biochar increased Cd immobilization by $10 \%$

\section{Introduction}

Due to industrialization and urbanization, soil cadmium (Cd) pollution is a global issue (Liao et al. 2015). Often this pollution is localized in areas of industrial activity. However, long range transport from industrial sources and the use of tainted water resources for irrigation have resulted in farmland accumulating high levels of contaminant (Lu et al. 2015a). In China the latest official soil surveys conclude that $19.4 \%$ of national farmland soils (based on the sampling points) has been contaminated (MEP 2014). Cd, along with $\mathrm{Hg}, \mathrm{As}, \mathrm{Cu}, \mathrm{Pb}, \mathrm{Cr}, \mathrm{Zn}$ and $\mathrm{Ni}$, are recognized to be priority risk drivers. $\mathrm{Cd}$ can migrate from contaminated soils to food crops, which can significantly increase human health risk associated with $\mathrm{Cd}$ poisoning (Ochoa et al. 2020). There is therefore an urgent need to develop efficient and scalable techniques for the remediation of farmland diffusely polluted with potentially toxic elements (PTEs). 
Biochar is the product of the pyrolysis of organic solid wastes under anoxic or limited oxygen conditions. Biochars can be produced from a wide range of organic feedstocks including crop straw, manure, wood chip, and sewage sludge (Wang and Wang 2019). Generally, biochar is alkaline, and contains abundant surface functional groups (Kloss et al. 2012). Several types of biochars have been reported to be efficient in immobilizing heavy metals through mechanisms such as adsorption, surface precipitation and electrostatic interaction (Chen et al. 2015; Alam et al. 2018). Biochar influence on Cd availability has been extensively studied over the last decade. For example, Lu et al. (2015b), Rehman et al. (2018), Li et al. (2019) and Bashir et al. (2020) all reported decreases in Cd bioavailability and reduced Cd accumulation into plants following biochar application to soil. In addition, biochars have been reported to improve soil properties, enhance soil fertility and increase crop yields (Laird et al. 2017). Thus, biochar amendment is considered as a cost-effective strategy for soil improvement and pollution abatement.

However, the properties of biochars can vary widely according to feedstock type used and the pyrolysis conditions applied (Liu et al. 2017; Qi et al. 2018; Zong et al. 2020). Zhao et al. (2013) produced twelve biochars pyrolyzed at $500^{\circ} \mathrm{C}$ and showed that both their surface areas and cation exchangeable capacities (CEC) varied considerably from $2.78 \mathrm{~m}^{2} / \mathrm{g}$ to $203 \mathrm{~m}^{2} / \mathrm{g}$ and $41.7 \mathrm{cmol} / \mathrm{kg}$ to $562 \mathrm{cmol} / \mathrm{kg}$, respectively. As a consequence of these contrasting properties, the twelve biochars exhibited different capacities for metal ion adsorption (Xu et al. 2013; Bashir et al. 2018). In addition, it has been reported that different biochar types applied to soil give rise to contrasting changes to the soil properties such as pH and CEC (Alburguerque et al. 2014; Zhang et al. 2016; Yuan et al. 2020). These soil factors further influence metal ion behaviour (Lu et al. 2017; Azhar et al. 2019). For instance, Novak et al. (2014) showed pecan shell biochar (produced at $350^{\circ} \mathrm{C}$ ) to increase soil $\mathrm{pH}$ from $5.6 \pm 0.1$ to $6.3 \pm 0.1$, while addition of poultry litter biochar (also produced at $350^{\circ} \mathrm{C}$ ) increase $\mathrm{pH}$ in the same soil to $8.4 \pm 0.1$. In another study, Fellete et al. (2014) reported extractable (using diethylenetriamine pentaacetic acid (DPTA)) Cd concentrations from soils amended with orchard residue biochar to decrease by $>70 \%$, while for fir tree biochar, Cd extractability decreased by only $12 \%$.

As briefly outlined above, most of these studies were conducted in laboratory or greenhouse settings. However, there is to date little information and guidance on field-scale in-situ applications of biochar. Moreover, where field trial results have been reported they have shown inconsistent outcomes, (Cui et al. 2016; O'Connor et al. 2018); these different outcomes being attributed to variable field conditions and contrasting biochar properties. There are also issues pertaining to the realism of biochar application rates applied in many of the published reports. Many authors have used biochar at very large application amounts, for example, 10-40 $\mathrm{t} \mathrm{ha}^{-1}$ (Chen et al. 2016; Cui et al. 2016; He et al. 2019). In a few studies, application rates of biochar have been even higher (up to 100-180 t/ha; Chan et al. 2008; Jeffery et al. 2011; Rajkovich et al. 2011; Rondon et al. 2014). Given the availability of biochar resource and the associated cost of biochar application, such large rates of biochar application at a field scale would likely be unfeasible. Importantly, it has been reported that decreases in metal availability, following biochar application, are not proportional to the amount of biochar applied (Bian et al. 2014); and, in Jeffery's meta-analysis (1483 studies), a poor relationship between biochar application rate and crop yield was 
reported $\left(r^{2}=0.1\right.$; Jeffery et al. 2011). It might therefore be concluded that high application rates of biochar may not be necessary to achieve desired outcomes. Thus, there a need to evaluate biochar efficacy to mitigate $\mathrm{Cd}$ phytoaccumulation using low application rates of biochar under field relevant conditions.

In this study, three biochars including rice straw biochar (RS), rice husk biochar (RH) and pig manure biochar (PM) were prepared and evaluated for their Cd adsorption capacities in the laboratory. The biochars were then used, in a field experiment at two low application rates (1.8 and 3.6 t/ha), under a crop of rape (Brassica campestris L.), to: i) evaluate their influence upon the accumulation of $\mathrm{Cd}$ from soils into the rape roots and edible parts; ii) to explore the mechanisms influencing Cd phytoaccumulation, and; iii) to provide evidence to assist the selection of biochar feedstock and biochar application rate for utilisation to abate risks associated with Cd pollution in soil.

\section{Materials And Methods}

\subsection{Biochar preparation}

Rice straw biochar (RS), rice husk biochar $(\mathrm{RH})$ and pig manure biochar $(\mathrm{PM})$ were produced using pilotscale biochar pyrolysis equipment $(\mathrm{L} 4.5 \mathrm{~m} \cdot \mathrm{W} 0.8 \mathrm{~m} \cdot \mathrm{H} 2 \mathrm{~m})$. The pyrolysis equipment comprised a pyrolysis chamber, a heating chamber, a feedstock supply system and a biochar output system. The equipment had an overall production capacity of 20 ton per year. Feedstocks were pyrolyzed in the pyrolysis chamber at $500^{\circ} \mathrm{C}$ for 1 hour under limited oxygen conditions. Thereafter, the biochars were ground through a $2 \mathrm{~mm}$ sieve. The physico-chemical properties of the three biochars were assessed using methods described in previous work (Zhang and Luo 2014; Zhang et al. 2016). Cd adsorption capacities of the biochars were characterized using batch equilibration adsorption experiments (full details are provided in the supporting information). Briefly, biochar $(50 \mathrm{mg}$ ) was shaken with $25 \mathrm{~mol} / \mathrm{L}-500 \mathrm{~mol} / \mathrm{L}$ $\mathrm{Cd}\left(\mathrm{NO}_{3}\right)_{2}$ solution $(5 \mathrm{~mL})$ at $25^{\circ} \mathrm{C}$ at $150 \mathrm{rpm}$ for 48 hours. Thereafter the suspensions were collected, and the concentration of $\mathrm{Cd}$ measured by inductively coupled plasma optical emission spectrometer (ICPOES) (Optima 7000DV; PerkinElmer Inc.).

\subsection{Field study}

The field experiment was conducted on an upland farm located in Zhouzai village $\left(24^{\circ} 23^{\prime} 26.08^{\prime \prime} \mathrm{N}\right.$, $\left.117^{\circ} 43^{\prime} 26.25 " E\right)$, Zhangzhou city, Fujian province in southern China. Local soils had been contaminated with potential toxic elements (PTEs); Cd being the primary pollutant. The concentration of $\mathrm{Cd}$ in the soil was $0.38 \mathrm{mg} / \mathrm{kg}$; this concentration exceeded the regulatory limit for agricultural soils $(0.30 \mathrm{mg} / \mathrm{kg}$; MEP 2018).

In November 2016, soil (0-20 cm) was ploughed. Biochars were then spread on the soil surface, and thoroughly mixed with the soils using a tillage machine (1GQN-120; Weifang shengxuan machines corporation). The applications of biochar were $0,1.8$ and $3.6 \mathrm{t} / \mathrm{ha}$, respectively. Each treatment was produced in triplicate. The area of each plot was $4 \mathrm{~m}^{2}$. Two weeks after biochar application, the land was 
rolled, and rape (Brassica campestris L.) seeds were sown. Irrigation and fertilizer management were performed according to the conventional practices of the local farmers and were identical on all plots.

\subsection{Sampling and analysis}

In January 2017, the rape plants were harvested. Three composite rape samples, each consisting of 10 plants randomly selected from each plot, were collected (resulting in nine composite rape samples for each treatment regime). Following their transfer to the laboratory, the rape samples were washed with deionized water. Thereafter, the rape samples were cut into two parts (the edible part and the root), and dried in the oven at $90^{\circ} \mathrm{C}$. For the analysis of Cd concentrations in the plants, subsamples of the edible part, or root, were crushed, ground, and passed through a $0.2 \mathrm{~mm}$ sieve. Samples of the edible part or root were then digested with $\mathrm{HNO}_{3}\left(65 \%\right.$, Merck, EMSURE $\left.{ }^{\text {TM }}\right)$ using a protocol modified from Zhu et al. (2008). For quality control, plant reference material (GBW 10015; purchased from the National Research Center for Standards in China) was digested and measured alongside the experimental samples, as were reagent blanks. The concentration of $\mathrm{Cd}$ in the digestates were analysed using an inductively coupled plasma mass spectrometry (ICP-MS 7500cx; Agilent Inc.). Concentrations of Cd were reported on dry weight basis. The recovery of $\mathrm{Cd}$ from the reference material was $108-113 \%$.

Nine soil samples $(0-20 \mathrm{~cm})$ were collected from each treatment. Soil samples were air-dried in the laboratory at room temperature, and then ground and passed through a $2 \mathrm{~mm}$ sieve. Subsamples of soils were ground and passed through a $0.15 \mathrm{~mm}$ sieve. The $\mathrm{pH}$ of soil samples was measured using a $\mathrm{pH}$ meter at the ratio of $1 \mathrm{~g}$ soil : $2.5 \mathrm{~mL}$ deionized water. The cation exchangeable capacity (CEC) of soil was measured using the $\mathrm{NH}_{4} \mathrm{OAc}-\mathrm{NaOAc}$ method (U.S. Environmental Protection Agency 1986). The concentrations of available $\mathrm{Cd}$ in soils were determined using a $0.01 \mathrm{~mol} / \mathrm{L} \mathrm{CaCl} \mathrm{C}_{2}$ extraction method (Houba et al. 1996). Briefly, soil samples were extracted with $0.01 \mathrm{~mol} / \mathrm{L} \mathrm{CaCl}_{2}$ solution at the ratio of $1 \mathrm{~g}$ soil : $\mathrm{CaCl}_{2}$ solution $(10 \mathrm{~mL})$. After 2 hours shaking, the suspensions were centrifuged, and the concentrations of $\mathrm{Cd}$ in the supernatant were measured using inductively coupled plasma mass spectrometry (ICP-MS 7500cx; Agilent Inc.).

\subsection{Data management and Statistic analysis}

All data were analysed using Microsoft Excel. The fitting of batch adsorption data was performed with OriginLab 2018 software (OriginLab Corp., USA). Statistical analysis of the data was performed with IBM SPSS Statistics 22.0 software (IBM Corp., USA). Significant differences among treatments were analyzed using one-way analysis of variance (ANOVA) (at $p<0.05$ level).

\section{Results}

\subsection{Biochar characterisation}

Properties varied across the three biochar types (Table 1). $\mathrm{pH}$ was always alkaline and ranged between 9.87 and 10.7; RS biochar had the highest pH (10.7). Carbon content in PM biochar was 20\%, while the C 
content in RS biochar or $\mathrm{RH}$ biochar was much higher ( $>40 \%)$. $\mathrm{N}$ and $\mathrm{O}$ contents in PM biochar were the highest amongst the three biochars (1.5\% and $20 \%$, respectively), while the $\mathrm{N}$ and $\mathrm{O}$ contents in $\mathrm{RH}$ biochar were lowest $(0.6 \%$ and $11 \%$, respectively). The ash content of PM biochar was particularly high (68\%; this accounting for the lower $\mathrm{C}$ content observed). The ash contents in the RS and RH biochars were much lower, $36 \%$ and $35 \%$, respectively. The surface topography and pore structure of the biochars also varied (Table 1 and Figs. S1-S2). The surface area of biochars followed the order of RS biochar $>$ PM biochar $>>\mathrm{RH}$ biochar, and the average pore volume of biochars followed the order of PM biochar $=\mathrm{RS}$ biochar > > RH biochar. The average pore size of PM biochar $(12.7 \mathrm{~nm})$ was the highest of the three biochars; average pore size in the RS and RH biochars were similar $(\sim 9.5 \mathrm{~nm})$. Based on these chemical and physical properties, it was hypothesised that the RS biochar (with high $\mathrm{pH}$, high carbon content and high surface area) would offer the best performance for Cd immobilisation (Chen et al. 2011; Shen et al. 2017; O’Connor et al. 2018). 
Table 1

Biochar properties

\begin{tabular}{|c|c|c|c|}
\hline & PM biochar & RS biochar & RH biochar \\
\hline $\mathrm{pH}$ & $9.87 \pm 0.01^{c}$ & $10.7 \pm 0.2^{\mathrm{a}}$ & $10.0 \pm 0.1^{\mathrm{b}}$ \\
\hline $\mathrm{pH}_{\mathrm{zpc}}$ & 9.48 & 9.53 & 8.91 \\
\hline $\mathrm{C}(\%)$ & $20.5 \pm 0.6^{a}$ & $41.7 \pm 0.7^{b}$ & $42.2 \pm 0.1^{\mathrm{b}}$ \\
\hline $\mathrm{N}(\%)$ & $1.51+0.03^{\mathrm{a}}$ & $1.06+0.03^{b}$ & $0.62+0.01^{c}$ \\
\hline $\mathrm{O}(\%)$ & $20.1 \pm 0.7^{a}$ & $12.0 \pm 1.0^{b}$ & $11.1 \pm 0.4^{b}$ \\
\hline$H(\%)$ & $1.25 \pm 0.03^{\mathrm{a}}$ & $2.01 \pm 0.07^{b}$ & $2.95 \pm 0.05^{\mathrm{C}}$ \\
\hline Ash (\%) & $67.9 \pm 0.4^{\mathrm{a}}$ & $35.9 \pm 0.4^{b}$ & $34.7 \pm 0.2^{b}$ \\
\hline \multicolumn{4}{|l|}{ Surface topography and pore structure } \\
\hline BET surface area $\left(\mathrm{m}^{2} / \mathrm{g}\right)$ & 4.13 & 4.92 & 2.28 \\
\hline Average pore volume $\left(\mathrm{m}^{3} / \mathrm{g}\right)$ & 0.014 & 0.012 & 0.006 \\
\hline Average pore size (nm) & 12.7 & 9.45 & 9.72 \\
\hline \multicolumn{4}{|l|}{ Surface functional groups } \\
\hline Carboxyl group $(\mathrm{mmol} / \mathrm{kg})$ & $0.25+0.0 .001^{b}$ & $0.63+0.13^{\mathrm{a}}$ & $0.25+0.001^{b}$ \\
\hline Phenolic group (mmol/kg) & $0.50+0.25^{a}$ & $0.38+0.18^{a}$ & $1.17+0.14^{b}$ \\
\hline Lactonic group $(\mathrm{mmol} / \mathrm{kg})$ & $0.75+0.01^{b}$ & $0.87+0.13^{b}$ & $1.33+0.14^{\mathrm{a}}$ \\
\hline Total acid functional group (mmol/kg) & $1.50+0.25^{\mathrm{a}}$ & $1.88+0.18^{\mathrm{a}}$ & $2.75+0.25^{b}$ \\
\hline Total base functional group $(\mathrm{mmol} / \mathrm{kg})$ & $2.38+0.13^{b}$ & $7.75+0.01^{a}$ & $0.50+0.001^{c}$ \\
\hline
\end{tabular}

Results of the batch equilibrium experiment indicated that $\mathrm{Cd}$ adsorption capacity of the three biochars followed the order: RS biochar > PM biochar > RH biochar (Fig. 1 and Table S1). Cd sorption onto both PM biochar and $\mathrm{RH}$ biochar were better fitted by the Freundlich isotherm model (rather than Langmuir isotherm model), while the RS biochar was fitted well with both the Langmuir and Freundlich isotherm models (Table S1). Given the model agreements, it was concluded that $\mathrm{Cd}$ adsorption onto the three biochars was likely attributable to chemical adsorption on heterogeneous surfaces (Zhang and Luo 2014). The value of $1 / \mathrm{n}$ in the Freundlich isotherm model followed the order of RS biochar < PM biochar < $\mathrm{RH}$ biochar. Since $1 / \mathrm{n}$ represented the adsorption affinity of metal ions onto adsorbent, this result 
confirmed that the adsorption of $\mathrm{Cd}^{2+}$ ion onto RS biochar was the greatest, while RH biochar showed lowest affinity for $\mathrm{Cd}$ ions.

\subsection{Effects of biochar amendment on the properties of field soils}

The $\mathrm{pH}$ in biochar amended soils were increased (from $5.06 \pm 0.03$ in the control, to $5.26 \pm 0.03-5.44 \pm$ 0.06 (PM), $5.30 \pm 0.07-5.30 \pm 0.19$ (RS) and $5.27 \pm 0.06-5.37 \pm 0.14$ (RH)) (Fig. 2a). However, no significant difference $(p>0.05)$ in soil $\mathrm{pH}$ were observed among three biochars.

CEC in the PM and RS amended soils were, respectively, $23.9 \mathrm{cmol} / \mathrm{kg}-24.8 \mathrm{cmol} / \mathrm{kg}$ and $23.0 \mathrm{cmol} / \mathrm{kg}$ $-24.3 \mathrm{cmol} / \mathrm{kg}$; these values were slightly higher, but not significantly different $(p>0.05)$, to that in the control (Fig. 2b). In contrast, soil amended with RH biochar had a lower, but not significantly different ( $p$ > 0.05), CEC $(20.0 \mathrm{cmol} / \mathrm{kg}-20.3 \mathrm{cmol} / \mathrm{kg})$.

Available Cd concentration in the control soil was $21.5 \pm 1.9 \mu \mathrm{g} / \mathrm{kg}$. Following biochar amendment, the available $\mathrm{Cd}$ concentrations were significantly lowered in all treatments $(p<0.05)$. However, greatest reductions in bioavailable $\mathrm{Cd}$ in soil were observed with PM amendment ( $43 \%$ and $51 \%$ reduction at 1.8 and $3.6 \mathrm{t} / \mathrm{ha}$ ) and RS amendment (29\% and $35 \%$ reduction at 1.8 and $3.6 \mathrm{t} / \mathrm{ha}$ ) (Fig. 3 ). In the treatments with $\mathrm{RH}$ biochar amendment, bioavailable $\mathrm{Cd}$ concentration was reduced by only $17 \%$ and $19 \%$ in the 1.8 $\mathrm{t} / \mathrm{ha}$ and $3.6 \mathrm{t} / \mathrm{ha}$ treatments, respectively.

\subsection{Effects of biochar amendment on the growths of rape plants in filed}

Biochar amendment influenced the growth of rape plants. Increases in dry weight of edible parts (Fig. S3a) and dry weight of roots (Fig. S3b) were observed in all instance following biochar amendment. However, these increases in biomass were marginal, and none were significantly different $(p>0.05)$ when compared to the control (except for the dry weight of root, in the treatment with $1.8 \mathrm{t} / \mathrm{ha}$ amendment of PM biochar).

\subsection{Effects of biochar amendment on Cd accumulation into plants}

In all instances, biochar amendment resulted in a decrease in the concentration of $\mathrm{Cd}$ in rape plant (Fig. 4). For the edible part of rape (Fig. 4a), the concentrations of $\mathrm{Cd}$ in the treatments with PM biochar were significantly $(p<0.05)$ decreased to $0.52 \pm 0.08 \mathrm{mg} / \mathrm{kg}(1.8 \mathrm{t} / \mathrm{ha})$ and $0.50 \pm 0.03 \mathrm{mg} / \mathrm{kg}(3.6 \mathrm{t} / \mathrm{ha})$; these levels were $70 \%$ and $68 \%$ of the control value. In the RS treatments, the Cd concentrations were significantly $(p<0.05)$ decreased to $0.51 \pm 0.09 \mathrm{mg} / \mathrm{kg}(1.8 \mathrm{t} / \mathrm{ha})$ and $0.51 \pm 0.02 \mathrm{mg} / \mathrm{kg}(3.6 \mathrm{t} / \mathrm{ha})$, respectively; these values were $70 \%$ of the control value. Following $\mathrm{RH}$ amendment, the concentrations of $\mathrm{Cd}$ in the edible part of rape were $0.66 \pm 0.04 \mathrm{mg} / \mathrm{kg}(1.8 \mathrm{t} / \mathrm{ha})$ and $0.67 \pm 0.03 \mathrm{mg} / \mathrm{kg}(3.6 \mathrm{t} / \mathrm{ha}) ;$ these values were approximately $89 \%$ of the control value. 
Regarding Cd concentrations in roots, treatments with PM biochar indicated decreased concentrations $(0.60 \pm 0.12 \mathrm{mg} / \mathrm{kg}(1.8 \mathrm{t} / \mathrm{ha})$ and $0.55 \pm 0.04 \mathrm{mg} / \mathrm{kg}$ (3.6 t/ha), compared to $0.74 \pm 0.30 \mathrm{mg} / \mathrm{kg}$ in the control (Fig. 4b). Similarly, the Cd concentrations in the treatments with RS biochar and RH biochar were also observed to decrease (to $0.50 \mathrm{mg} / \mathrm{kg}-0.52 \mathrm{mg} / \mathrm{kg}$ and $0.51 \mathrm{mg} / \mathrm{kg}-0.65 \mathrm{mg} / \mathrm{kg}$, in $1.8 \mathrm{t} / \mathrm{ha}$ and 3.6 $t /$ ha, respectively). Where application rate was equivalent, no significant differences $(p>0.05)$ were observed across the three biochar types.

\section{Discussion}

The $\mathrm{C}$ content of the RS and RH biochar ( 42\%) was more than 2 times that of the PM biochar; while the content of $\mathrm{N}$ in PM biochar was 1.9 times the content in RS biochar, and 3.3 times the content in $\mathrm{RH}$ biochar (Table 1). In agreement with previous reports, the biochars prepared from manure contained lower $\mathrm{C}$ and higher $\mathrm{N}$ than the biochars prepared from plant residues (Xu et al. 2013; Zornoza et al. 2016). Such differences have previously been attributed to differences in the element composition of feedstocks (Zhao et al. 2013). In addition, the three biochars had different surface topography and pore structure (Fig. S1). The surface area, average pore volume and average pore size of PM biochar and RS biochar were all higher than those for $\mathrm{RH}$ biochar (Table 1), indicating PM biochar and $\mathrm{RH}$ biochar offer higher pore structures than $\mathrm{RH}$ biochar. This finding is in good agreement with previous literature highlighting that contrasting feedstock sources produced biochars with different physical and chemical properties (Sun et al. 2014; Hyväluoma et al. 2018).

The properties of biochar including surface area, distribution of surface functional groups, ash content and $\mathrm{pH}$, play important roles during metal adsorption (Uchimiya et al. 2011; Jiang et al. 2016). As a consequence of differing physical and chemical properties, the sorption capacities of the three biochars varied (Fig. 1). Complexation of metals, through ion exchange interactions, with ionized surfaces and oxygen-containing functional groups (i.e. carboxyl $(-\mathrm{COOH})$, hydroxyl $(-\mathrm{OH})$, phenol $(\mathrm{R}-\mathrm{OH})$ groups) has been suggested as an important mechanism for metal sorption by biochar (Kołodyńska et al. 2017). In this study, RS biochar had highest surface area and highest content of surface functional groups (Table 1), available to prompt interactions with metal ions. Similarly, since the BET surface area and the content of surface functional groups of $\mathrm{RH}$ biochar were lowest among three biochars (Table 1), the sorption of $\mathrm{Cd}^{2+}$ ions onto $\mathrm{RH}$ biochar was correspondingly lower. In addition, the $\mathrm{pH}$ of three biochars also influenced the equilibrium $\mathrm{pH}$ and thus the adsorption of $\mathrm{Cd}$ ions (Fig. S4). The sorption of more $\mathrm{Cd}^{2+}$ ion with increasing $\mathrm{pH}$ is consistent with Zhang and Luo (2014) who also reported this relationship. In the batch experiments, the addition of $\mathrm{RS}$ biochar with highest $\mathrm{pH}$ lead to highest equilibrium $\mathrm{pH}$ among three biochars (Table S3); this, likely, underpinned the greatest sorption of $\mathrm{Cd}^{2+}$ ions onto RS biochar. Overall the $\mathrm{RH}$ equilibrium $\mathrm{pH}$ was lower than $\mathrm{RS}$ or $\mathrm{PM}$, and $\mathrm{Cd}^{2+}$ ion sorption was also lower.

When amended to soil, biochars increased soil pH in all instances, but the increases were not significantly different ( $p>0.05$ ) among the three biochars (Fig. 2a). In addition, biochar had limited influenced on soil CEC (Fig. 2b). These outcomes are likely due to the low amendment levels ( 1.8 and $3.6 \mathrm{t} / \mathrm{ha}$ ). Nonetheless, all three biochars significantly $(p<0.05)$ reduced extractable $C d$ concentrations (decreases 
followed the order: PM biochar $>$ RS biochar $>$ RH biochar) (Fig. 3). It is suggested, therefore, that changes in $\mathrm{Cd}$ availability were most likely linked to $\mathrm{Cd}$ ion interaction with biochar (rather than changes to the soil chemical environment). Reduced concentrations of available $\mathrm{Cd}$ were translated into observed reductions in Cd content in rape plants (Fig. 4 and Table S2). Importantly, the three types of biochar led to different outcomes for Cd-plant interactions. Treatment with $\mathrm{RH}$ biochar was relatively ineffective, while amendment with PM or RS biochar resulted in much more effective abatement of soil to plant transfer of Cd. Very little difference was observed where 1.8 and $3.6 \mathrm{t} / \mathrm{ha}$ application levels of the same biochar were compared. This observation suggesting, even at the lowest application rate (1.8 $\mathrm{t} / \mathrm{ha})$, that PM and RS biochars were effective ameliorants. The literature, in many cases, has reported metal-biochar-soil-plant interactions to result in large decreases in phytoaccumulation of metals into numerous crop types (Zhang et al. 2013; Puga et al. 2015; Xu et al. 2016; Younis et al. 2016; Zhang et al. 2016; Mohamed et al. 2017); while other cases this ameliorative influence has been reported to be minimal (Fellet et al. 2014; Hu et al. 2014; Lucchini et al. 2014; Kloss et al. 2015; Ree et al. 2015; Zhang et al. 2017). For instance, Zhang et al. (2017) reported that the amendment of biochar into heavily contaminated soils to have either no effect, or even to promote $\mathrm{Cd}$ accumulation into lettuce shoots. Wang et al. (2019) conducted a pot experiment with four types of biochar including wood biochar, rice straw biochar, Chinese walnut shell biochar and bamboo biochar. These authors reported none of the biochar amendments to influence $\mathrm{Cu}$ concentration of stems, leaves and roots of moso bamboo, while $\mathrm{Cd}$ concentrations decreased in all cases. The $\mathrm{Zn}$ accumulation in roots of moso bamboo was decreased in treatments with biochar, except bamboo biochar, while only wood biochar amendment reduced $\mathrm{Zn}$ concentration in plant stems and leaves. However, in the present study, RS and PM biochars (applied at low-levels: 1.8 and $3.6 \mathrm{t} / \mathrm{ha}$ ) were established to be effective for the control of Cd phytoaccumulation, while RH biochar was observed to have only a limited effect.

While Cd sorption capacity of RS biochar was higher than that of PM biochar in the batch adsorption experiment, there were no significant difference between the decreased magnitude of $\mathrm{Cd}$ concentrations in rape plants where RS and PM treatments were compared (Fig. 4). These results highlight that the performance of these biochars in the batch adsorption experiments and in real soil systems were not consistent. This outcome is consistent with Uchimiya et al. (2010) who reported biochars produced from broiler litter manure at $350{ }^{\circ} \mathrm{C}(350 \mathrm{BL})$ removed more $\mathrm{Ni}^{2+}$ and $\mathrm{Cd}^{2+}$ ions than biochars produced at 700 ${ }^{\circ} \mathrm{C}(700 \mathrm{BL})$; but when applied (at $5 \%-10 \%(\mathrm{w} / \mathrm{w})$ ), to soil the 350BL treatment contained higher soluble metal concentrations than the $700 \mathrm{BL}$ treated soils. Although the $350 \mathrm{BL}$ had a higher adsorption capacity than the 700BL, its lower ability to increase soil pH underpinned the less effective immobilization of metals in soil by 350BL. Similarly, the $\mathrm{pH}$ increase, rather than primary Cd-biochar interaction, has also been proposed by other researchers (Houben et al. 2013; Rees et al. 2014). Thus, it is recommended that, before field scale deployment, biochar sorption capacity should be established in the presence of the soil it is intended to remediate.

In the present study, the $\mathrm{pH}$ of biochar amended soils were increased by $0.2-0.4$ unit, while slight (although non-significant) changes in soil CEC were observed following biochar amendment. The 
minimal affect is most likely due to the low level of biochar applied (1.8t/ha - 3.6 t/ha). Given that soil chemical properties ( $\mathrm{pH}$ and $\mathrm{CEC}$ ) were largely unchanged it is suggested that the primary interactions between $\mathrm{Cd}$ and the biochars were likely responsible for the outcomes observed.

The application of RS biochar or PM biochar at low level (1.8 t/ha) was effective to mitigate the transfer of $\mathrm{Cd}$ from soil into crop. With a doubling in application rates, the decrease of soil available $\mathrm{Cd}$ concentrations were increased (on average by approximately extra 10\%), but the concentrations of Cd in rape showed limited change. It is highlighted that in the present research, the soil was not heavily contaminated. The soil Cd concentration $(0.38 \mathrm{mg} / \mathrm{kg})$ only just exceeding the regulatory limit of 0.30 $\mathrm{mg} / \mathrm{kg}$ (MEP 2018). It is therefore emphasized that the low application rates of bichar were directed at a small excess of $\mathrm{Cd}$ in the soil system (this likely underpinned the successful outcomes observed) and that the lower application rate was sufficient to accommodate the excess of $\mathrm{Cd}$. It follows that should soil Cd concentrations are much higher, such an outcome might not transpire and larger applications of biochar could be needed to accommodate a greater excess of $\mathrm{Cd}$ in the soil system. This said, Nie et al. (2018) reported the low level (1.5-3.0 t/ha) application of sugarcane bagasse biochar decreased the concentrations of $\mathrm{Cd}, \mathrm{Pb}$ and $\mathrm{Cu}$ in pak choi by $62-76 \%, 17.3-49.1 \%$ and $15-38 \%$, respectively. In contrast to the present study, the concentrations of $\mathrm{Cd}, \mathrm{Cu}$ and $\mathrm{Pb}$ in this experimental were $1.4 \mathrm{mg} / \mathrm{kg}$, $278 \mathrm{mg} / \mathrm{kg}$ and $348 \mathrm{mg} / \mathrm{kg}$; Cd being more than 4 times the regulatory limit. Overall, the results of the current research support low-level application (i.e. $1.8 \mathrm{t} / \mathrm{ha}$ ) of biochar to mitigate the transfer of $\mathrm{Cd}$ from soil to rape plants.

It is highlighted that many of the results reported in the literature relate to biochars that are produced in small quantities in the laboratory (Alburquerque et al. 2014; Zornoza et al. 2016; Bashir et al. 2018; Azhar et al. 2019). In contrast, the present study considered biochars produced using a larger pyrolysis system. The pilot scale pyrolysis system used to produce the biochars for this present research had an output capacity of 20 ton per year. Thus, assuming an application rate of $2 \mathrm{t} / \mathrm{ha}$, such a unit could service 10 ha p.a. It is emphasised that this scale of production, and low application rates, represents a realistic approach to support the production of biochar in quantities that would allow for meaningful field scale application. Given the extent of diffuse pollution associated with a considerable proportion of China's farmland (Lu et al. 2015a; Sun et al. 2019) and the predominance of small farms ( $<0.6 \mathrm{ha}$ ) across much of China (particularly remote rural regions) (Zhang 2017), the collective research findings demonstrates the genuine reality of biochar-based remediation solutions to meaningfully contribute to mitigating some of the diffused contamination associated with tainted farmland.

\section{Conclusions}

Biochars derived from different feedstocks, under identical pyrolysis conditions, showed different sorption capacities for $\mathrm{Cd}^{2+}$ ions. Following amendment to soil, even at low application rates (1.8 t/ha), all biochars were observed to reduce the available concentrations of $\mathrm{Cd}$ in soil; slightly higher $\mathrm{Cd}$ immobilisation was observed at $3.6 \mathrm{t} /$ ha (an average increase of $10 \%$ ). These changes in Cd availability resulted in decreased $\mathrm{Cd}$ concentrations in rape plants. Biochars derived from pig manure (PM) or rice 
straw (RS) led to much lower Cd concentrations in rape plants when compared to outcomes for rice husk $(\mathrm{RH})$ biochar. Results underline that favorable Cd-biochar sorption capacities, established in the absence of soil under laboratory batch sorption conditions, did not necessarily translate into comparable success in metal pollution amelioration under field conditions. These results highlight the need to trail biochars, in the presence of the soil to be targeted for remediation, before full scale deployment is undertaken.

Importantly, this research has validated an approach, that is relevant in terms of both biochar production rate and application rate, for meaningful engagement with the amelioration of Cd-tainted farmland in China at a realistic scale.

\section{Declarations}

\section{Author contribution}

C Cai and YC Zhang conceived and designed the study; JJ Fan and SN Lin performed the experiment; YW Hou analyzed the data; YC Zhang drafted the manuscript; BJ Reid and F Coulon revised the manuscript; C Cai approved the final version of manuscript.

\section{Funding}

This work was financially supported by grants from National Key R\&D Project (2018YFC1802703, 2016YFD0800706) and the Science and Technology Project of Xiamen city (3502Z20182001).

\section{Ethics approval and consent to participate}

Not applicable.

\section{Consent for publication}

Not applicable.

\section{Availability of data and materials}

The data that support the findings of this study are available from the corresponding author upon reasonable request.

\section{Competing interests}

The authors declare no competing interests.

\section{References}

1. Alam MS, Gorman-Lewis D, Chen N et al (2018) Thermodynamic Analysis of Nickel(II) and Zinc(II) Adsorption to Biochar. Environ Sci Technol 52: 6246-6255. https://doi.org/10.1021/acs.est.7b06261. 
2. Alburquerque JA, Calero JM, Barrón V et al (2014) Effects of biochars produced from different feedstocks on soil properties and sunflower growth. J Plant Nutr Soil Sci 177: 16-25. https://doi.org/10.1002/jpln.201200652.

3. Azhar M, Zia ur Rehman M, Ali S et al (2019) Comparative effectiveness of different biochars and conventional organic materials on growth, photosynthesis and cadmium accumulation in cereals. Chemosphere 227: 72-81. https://doi.org/10.1016/j.chemosphere.2019.04.041.

4. Bashir S, Hussain Q, Shaaban M et al (2018) Efficiency and surface characterization of different plant derived biochar for cadmium (Cd) mobility, bioaccessibility and bioavailability to Chinese cabbage in highly contaminated soil. Chemosphere 211: 632-639. https://doi.org/10.1016/j.chemosphere.2018.07.168.

5. Bian R, Joseph S, Cui L et al (2014) A three-year experiment confirms continuous immobilization of cadmium and lead in contaminated paddy field with biochar amendment. J Hazard Mater 272: 121128. https://doi.org/10.1016/j.jhazmat.2014.03.017.

6. Chan KY, Van Zwieten L, Meszaros I et al (2008) Agronomic values of greenwaste biochar as a soil amendment. Soil Res 45(8): 629-634. https://doi.rog/ 10.1071/SR07109

7. Chen D, Guo H, Li R et al (2016) Low uptake affinity cultivars with biochar to tackle Cd-tainted rice A field study over four rice seasons in Hunan, China. Sci Total Environ 541: 1489-1498. https://doi.org/10.1016/j.scitotenv.2015.10.052.

8. Chen T, Zhou Z, Han R et al (2015) Adsorption of cadmium by biochar derived from municipal sewage sludge: Impact factors and adsorption mechanism. Chemosphere 134: 286-293. https://doi.org/10.1016/j.chemosphere.2015.04.052.

9. Chen X, Chen G, Chen L et al (2011) Adsorption of copper and zinc by biochars produced from pyrolysis of hardwood and corn straw in aqueous solution. Biores Technol 102: 8877-8884. https://doi.org/10.1016/j.biortech.2011.06.078.

10. Cui L, Pan G, Li L et al (2016) Continuous immobilization of cadmium and lead in biochar amended contaminated paddy soil: A five-year field experiment. Ecol Eng 93: 1-8. https://doi.org/10.1016/j.ecoleng.2016.05.007.

11. Fellet G, Marmiroli M Marchiol L (2014) Elements uptake by metal accumulator species grown on mine tailings amended with three types of biochar. Sci Total Environ 468-469: 598-608. https://doi.org/10.1016/j.scitotenv.2013.08.072.

12. He L, Zhong H, Liu G et al (2019) Remediation of heavy metal contaminated soils by biochar: Mechanisms, potential risks and applications in China. Environ Pollut 252: 846-855. https://doi.org/10.1016/j.envpol.2019.05.151.

13. Houba VJG, Lexmond TM, Novozamsky I et al (1996) State of the art and future developments in soil analysis for bioavailability assessment. Sci Total Environ 178: 21-28. https://doi.org/10.1016/00489697(95)04793-X.

14. Houben D, Evrard L Sonnet $\mathrm{P}$ (2013) Mobility, bioavailability and pH-dependent leaching of cadmium, zinc and lead in a contaminated soil amended with biochar. Chemosphere 92: 1450-1457. 
https://doi.org/10.1016/j.chemosphere.2013.03.055.

15. Hu J, Wu F, Wu S et al (2014) Biochar and Glomus caledonium influence Cd accumulation of upland kangkong (Ipomoea aquatica Forsk.) intercropped with Alfred stonecrop (Sedum alfredii Hance). Sci. Rep-UK 4: 4671.

16. Hyväluoma J, Kulju S, Hannula M et al (2018) Quantitative characterization of pore structure of several biochars with 3D imaging. Environmental Science and Pollution Research 25: 25648-25658. 10.1007/s11356-017-8823-x.

17. Jeffery $S$, Verheijen FGA, van der Velde M et al (2011) A quantitative review of the effects of biochar application to soils on crop productivity using meta-analysis. Agr Ecosys Environ 144: 175-187. https://doi.org/10.1016/j.agee.2011.08.015.

18. Jiang S, Huang L, Nguyen TAH et al (2016) Copper and zinc adsorption by softwood and hardwood biochars under elevated sulphate-induced salinity and acidic $\mathrm{pH}$ conditions. Chemosphere 142: 6471. https://doi.org/10.1016/j.chemosphere.2015.06.079.

19. Kloss S, Zehetner F, Buecker J et al (2015) Trace element biogeochemistry in the soil-water-plant system of a temperate agricultural soil amended with different biochars. Environ Sci Pollut Res 22: 4513-4526. 10.1007/s11356-014-3685-y.

20. Kloss S, Zehetner F, Dellantonio A et al (2012) Characterization of Slow Pyrolysis Biochars: Effects of Feedstocks and Pyrolysis Temperature on Biochar Properties. J Environ Qual 41: 990-1000. https://doi.org/10.2134/jeq2011.0070.

21. Kołodyńska D, Krukowska J Thomas P (2017) Comparison of sorption and desorption studies of heavy metal ions from biochar and commercial active carbon. Chemical Engineering Journal 307: 353-363. https://doi.org/10.1016/j.cej.2016.08.088.

22. Kołodyńska D, Krukowska J Thomas P (2017) Comparison of sorption and desorption studies of heavy metal ions from biochar and commercial active carbon. Chem Eng J 307: 353-363. https://doi.org/10.1016/j.cej.2016.08.088.

23. Laird DA, Novak JM, Collins HP et al (2017) Multi-year and multi-location soil quality and crop biomass yield responses to hardwood fast pyrolysis biochar. Geoderma 289: 46-53. https://doi.org/10.1016/j.geoderma.2016.11.025.

24. Li S, Wang M, Zhao Z et al (2019) Use of soil amendments to reduce cadmium accumulation in rice by changing $\mathrm{Cd}$ distribution in soil aggregates. Environ Sci Pollut Res: 1-10.

25. Liao QL, Liu C, Wu HY et al (2015) Association of soil cadmium contamination with ceramic industry: A case study in a Chinese town. Sci Total Environ 514: 26-32. https://doi.org/10.1016/j.scitotenv.2015.01.084.

26. Liu Y, Yao S, Wang Y et al (2017) Bio- and hydrochars from rice straw and pig manure: Intercomparison. Biores Technol 235: 332-337. https://doi.org/10.1016/j.biortech.2017.03.103.

27. Lu H, Li Z, Fu S et al (2015) Effect of Biochar in Cadmium Availability and Soil Biological Activity in an Anthrosol Following Acid Rain Deposition and Aging. Water Air Soil Pollut 226: 164. 10.1007/s11270-015-2401-y. 
28. Lu K, Yang X, Gielen G et al (2017) Effect of bamboo and rice straw biochars on the mobility and redistribution of heavy metals $(\mathrm{Cd}, \mathrm{Cu}, \mathrm{Pb}$ and $\mathrm{Zn}$ ) in contaminated soil. J Environ Manage 186: 285292.

29. Lu Y, Song S, Wang R et al (2015) Impacts of soil and water pollution on food safety and health risks in China. Environ Inter 77: 5-15. https://doi.org/10.1016/j.envint.2014.12.010.

30. Lucchini P, Quilliam RS, DeLuca TH et al (2014) Does biochar application alter heavy metal dynamics in agricultural soil? Agr Ecosys Environ 184: 149-157. https://doi.org/10.1016/j.agee.2013.11.018.

31. MEP (Ministry of Environmental Protection of the People's Republic of China) (2014) Q\&A for nationwide soil pollution survey report.

http://www.zhb.gov.cn/gkml/hbb/qt/201404/t20140417_270671.htm (In Chinese).

32. MEP (Ministry of Environmental Protection of the People's Republic of China) (2018) Soil environmental quality: Risk control standard for contaminated agricultural soils (GB 15618-2018), Beijing, China.

33. Mohamed BA, Ellis N, Kim CS et al (2017) The role of tailored biochar in increasing plant growth, and reducing bioavailability, phytotoxicity, and uptake of heavy metals in contaminated soil. Environ Pollut 230: 329-338. https://doi.org/10.1016/j.envpol.2017.06.075.

34. Nie C, Yang X, Niazi NK et al (2018) Impact of sugarcane bagasse-derived biochar on heavy metal availability and microbial activity: A field study. Chemosphere 200: 274-282. https://doi.org/10.1016/j.chemosphere.2018.02.134.

35. Novak JM, Cantrell KB, Watts DW et al (2014) Designing relevant biochars as soil amendments using lignocellulosic-based and manure-based feedstocks. J Soil Sediment 14: 330-343. 10.1007/s11368013-0680-8.

36. Ochoa M, Tierra W, Tupuna-Yerovi DS et al (2020) Assessment of cadmium and lead contamination in rice farming soils and rice (Oryza sativa L.) from Guayas province in Ecuador. Environ Pollut 260: 114050. https://doi.org/10.1016/j.envpol.2020.114050.

37. O'Connor D, Peng T, Zhang J et al (2018) Biochar application for the remediation of heavy metal polluted land: A review of in situ field trials. Sci Total Environ 619-620: 815-826. https://doi.org/10.1016/j.scitotenv.2017.11.132.

38. Puga AP, Abreu CA, Melo LCA et al (2015) Cadmium, lead, and zinc mobility and plant uptake in a mine soil amended with sugarcane straw biochar. Environ Sci Pollut Res 22: 17606-17614. 10.1007/s11356-015-4977-6.

39. Qi F, Lamb D, Naidu R et al (2018) Cadmium solubility and bioavailability in soils amended with acidic and neutral biochar. Sci Total Environ 610-611: 1457-1466. https://doi.org/10.1016/j.scitotenv.2017.08.228.

40. Rajkovich S, Enders A, Hanley K et al (2012) Corn growth and nitrogen nutrition after additions of biochars with varying properties to a temperate soil. Biol Fert Soils 48: 271-284. 10.1007/s00374011-0624-7. 
41. Rees F, Simonnot MO Morel JL (2014) Short-term effects of biochar on soil heavy metal mobility are controlled by intra-particle diffusion and soil pH increase. Eur J Soil Sci 65: 149-161. https://doi.org/10.1111/ejss.12107.

42. Rehman MZu, Rizwan M, Hussain A et al (2018) Alleviation of cadmium (Cd) toxicity and minimizing its uptake in wheat (Triticum aestivum) by using organic carbon sources in Cd-spiked soil. Environ Pollut 241: 557-565. https://doi.org/10.1016/j.envpol.2018.06.005.

43. Rondon MA, Lehmann J, Ramírez J et al (2007) Biological nitrogen fixation by common beans (Phaseolus vulgaris L.) increases with bio-char additions. Biol Fert Soils 43: 699-708. 10.1007/s00374-006-0152-z.

44. Shen Z, Zhang Y, McMillan $O$ et al (2017) Characteristics and mechanisms of nickel adsorption on biochars produced from wheat straw pellets and rice husk. Environ Sci Pollut Res 24: 12809-12819. 10.1007/s11356-017-8847-2.

45. Sun Y, Gao B, Yao Y et al (2014) Effects of feedstock type, production method, and pyrolysis temperature on biochar and hydrochar properties. Chem Eng J 240: 574-578. https://doi.org/10.1016/j.cej.2013.10.081.

46. Sun Y, Li H, Guo G et al (2019) Soil contamination in China: Current priorities, defining background levels and standards for heavy metals. J Environ Manage 251: 109512. https://doi.org/10.1016/j.jenvman.2019.109512.

47. Uchimiya M, Chang S Klasson KT (2011) Screening biochars for heavy metal retention in soil: Role of oxygen functional groups. J Hazard Mater 190: 432-441. https://doi.org/10.1016/j.jhazmat.2011.03.063.

48. Uchimiya M, Lima IM, Thomas Klasson K et al (2010) Immobilization of Heavy Metal lons (Cull, CdII, Nill, and PbII) by Broiler Litter-Derived Biochars in Water and Soil. J Agr Food Chem 58: 5538-5544. $10.1021 /$ jf 9044217.

49. S. Environmental Protection Agency (1986). Cation-exchange capacity of soils (sodium acetate) (SW846 Method 9081), Washington, DC, USA.

50. Wang J Wang S (2019) Preparation, modification and environmental application of biochar: A review. J Clean Prod 227: 1002-1022. https://doi.org/10.1016/j.jclepro.2019.04.282.

51. Wang Y, Zhong B, Shafi M et al (2019) Effects of biochar on growth, and heavy metals accumulation of moso bamboo (Phyllostachy pubescens), soil physical properties, and heavy metals solubility in soil. Chemosphere 219: 510-516. https://doi.org/10.1016/j.chemosphere.2018.11.159.

52. Xu P, Sun C-X, Ye X-Z et al (2016) The effect of biochar and crop straws on heavy metal bioavailability and plant accumulation in a $\mathrm{Cd}$ and $\mathrm{Pb}$ polluted soil. Ecotox Environ Safe 132: 94-100. https://doi.org/10.1016/j.ecoenv.2016.05.031.

53. Xu X, Cao X Zhao L (2013) Comparison of rice husk- and dairy manure-derived biochars for simultaneously removing heavy metals from aqueous solutions: Role of mineral components in biochars. Chemosphere 92: 955-961. https://doi.org/10.1016/j.chemosphere.2013.03.009. 
54. Younis U, Malik SA, Rizwan M et al (2016) Biochar enhances the cadmium tolerance in spinach (Spinacia oleracea) through modification of Cd uptake and physiological and biochemical attributes. Environ Sci Pollut Res 23: 21385-21394. 10.1007/s11356-016-7344-3.

55. Yuan C, Gao B, Peng Y et al (2021) A meta-analysis of heavy metal bioavailability response to biochar aging: Importance of soil and biochar properties. Sci Total Environ 756: 144058. https://doi.org/10.1016/j.scitotenv.2020.144058.

56. Zhang R-H, Li Z-G, Liu X-D et al (2017) Immobilization and bioavailability of heavy metals in greenhouse soils amended with rice straw-derived biochar. Ecol Eng 98: 183-188. https://doi.org/10.1016/j.ecoleng.2016.10.057.

57. Zhang Y, Chen T, Liao Y et al (2016) Modest amendment of sewage sludge biochar to reduce the accumulation of cadmium into rice(Oryza sativa L.): A field study. Environ Pollut 216: 819-825. https://doi.org/10.1016/j.envpol.2016.06.053.

58. Zhang Y, Luo W (2014) Adsorptive removal of heavy metal from acidic wastewater with biochar produced from anaerobically digested residues: kinetics and surface complexation modeling. BioResources 9(2): 2484-2499.

59. Zhang Z, Solaiman ZM, Meney K et al (2013) Biochars immobilize soil cadmium, but do not improve growth of emergent wetland species Juncus subsecundus in cadmium-contaminated soil. J Soil Sediment 13: 140-151. 10.1007/s11368-012-0571-4.

60. Zhang RH, Li ZG, Liu XD et al (2017) Immobilization and bioavailability of heavy metals in greenhouse soils amended with rice straw-derived biochar. Ecol Eng 98: 183-188.

61. Zhang BB (2017) Theory, model and route on spatial recombination of arable land use system based on land fragmentation perspective. PhD Thesis, China Agricultural University.

62. Zhao L, Cao X, Mašek $O$ et al (2013) Heterogeneity of biochar properties as a function of feedstock sources and production temperatures. J Hazard Mater 256-257: 1-9. https://doi.org/10.1016/j.jhazmat.2013.04.015.

63. Zhu YG, Sun GX, Lei M et al (2008) High Percentage Inorganic Arsenic Content of Mining Impacted and Nonimpacted Chinese Rice. Environ Sci Technol 42: 5008-5013. 10.1021/es8001103.

64. Zong Y, Xiao Q Lu S (2021) Biochar derived from cadmium-contaminated rice straw at various pyrolysis temperatures: Cadmium immobilization mechanisms and environmental implication. Biores Technol 321: 124459. https://doi.org/10.1016/j.biortech.2020.124459.

65. Zornoza R, Moreno-Barriga F, Acosta JA et al (2016) Stability, nutrient availability and hydrophobicity of biochars derived from manure, crop residues, and municipal solid waste for their use as soil amendments. Chemosphere 144: 122-130. https://doi.org/10.1016/j.chemosphere.2015.08.046.

\section{Figures}




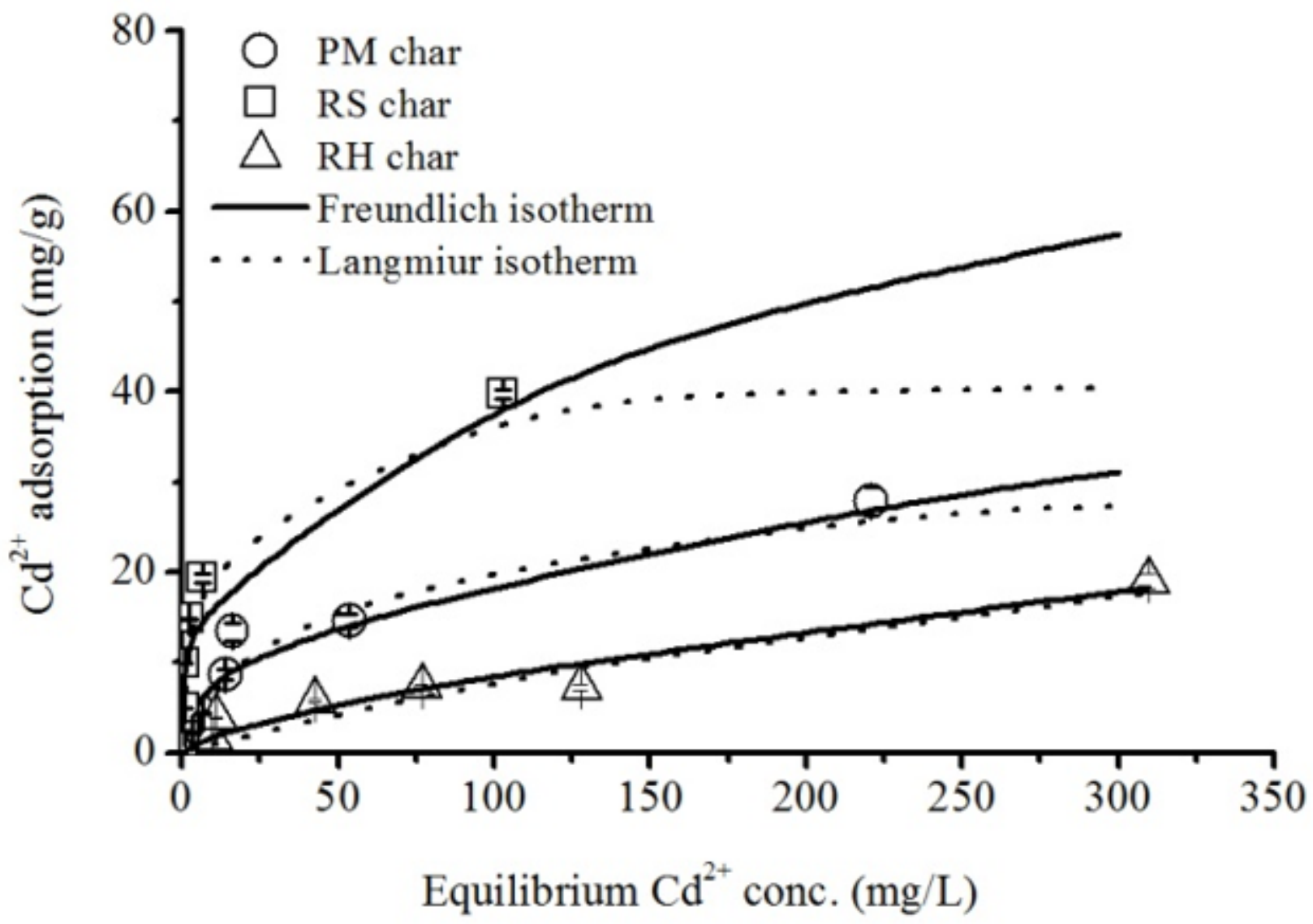

Figure 1

Adsorption isotherm of Cd2+ ions onto PM biochar (circles), RS biochar (squares) and RH biochar (triangles). 
a)

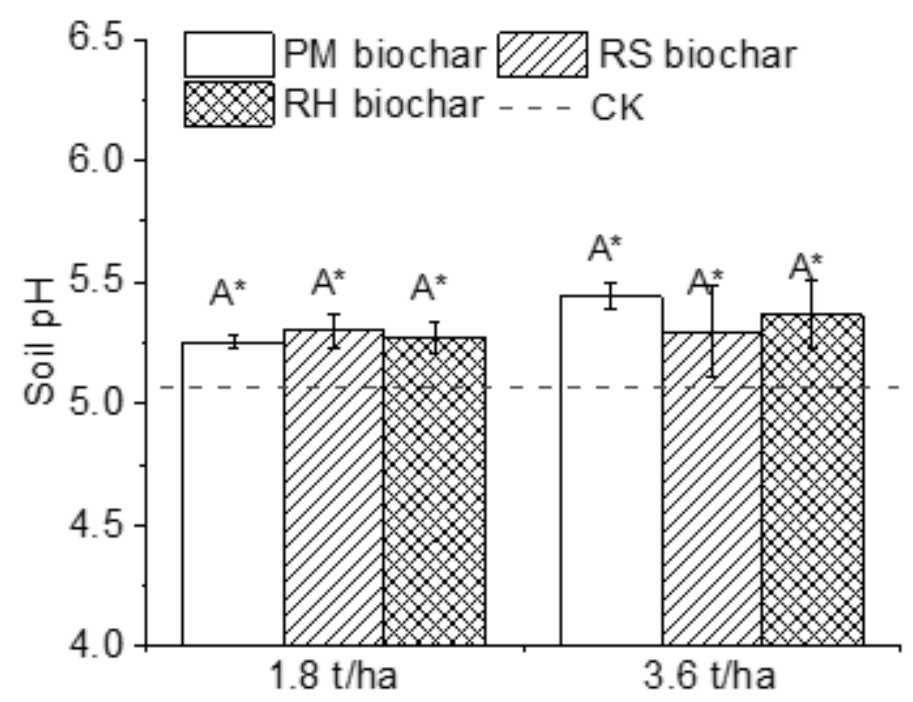

b)

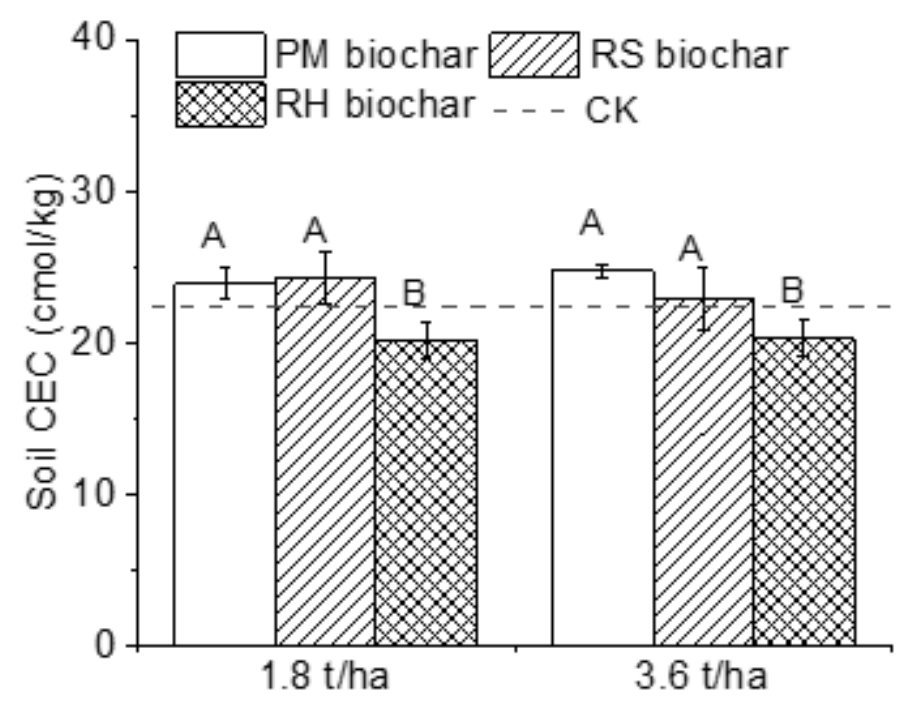

Figure 2

Changes in the properties of soil and soil amended with biochars. " $*$ " indicates a value to be significantly different to the control $(C K)$ value $(p<0.05)$. Like uppercase letters indicate no significant difference $(p>$ 0.05 ) between groups with biochar amendment at like application rates. 


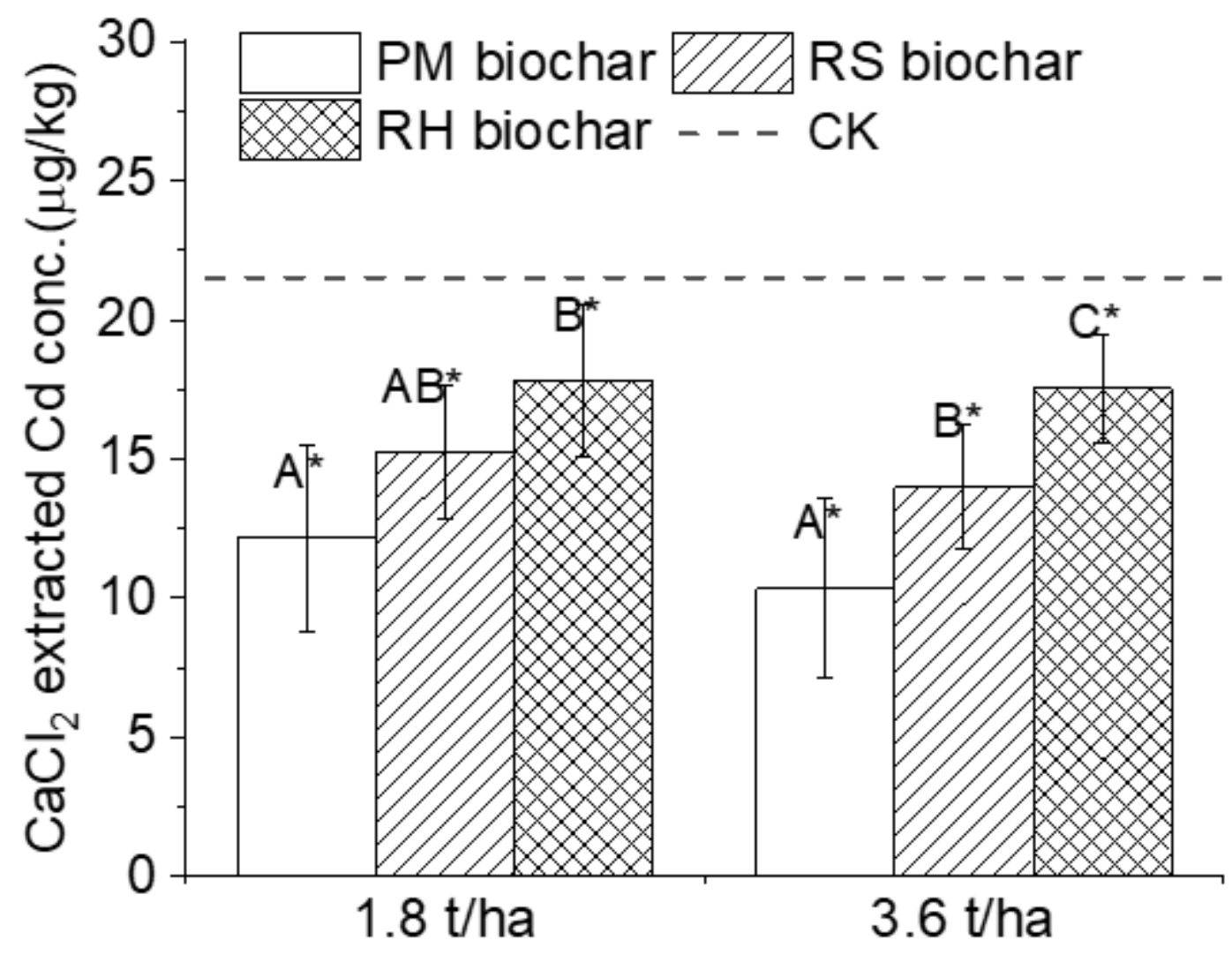

Figure 3

Available $\mathrm{Cd}$ concentrations in soil and soil amended with biochars. "*" indicates a value to be significantly different to the control (CK) value $(p<0.05)$. Like uppercase letters indicate no significant difference $(p>0.05)$ between groups with biochar amendment at like application rates. 
a)

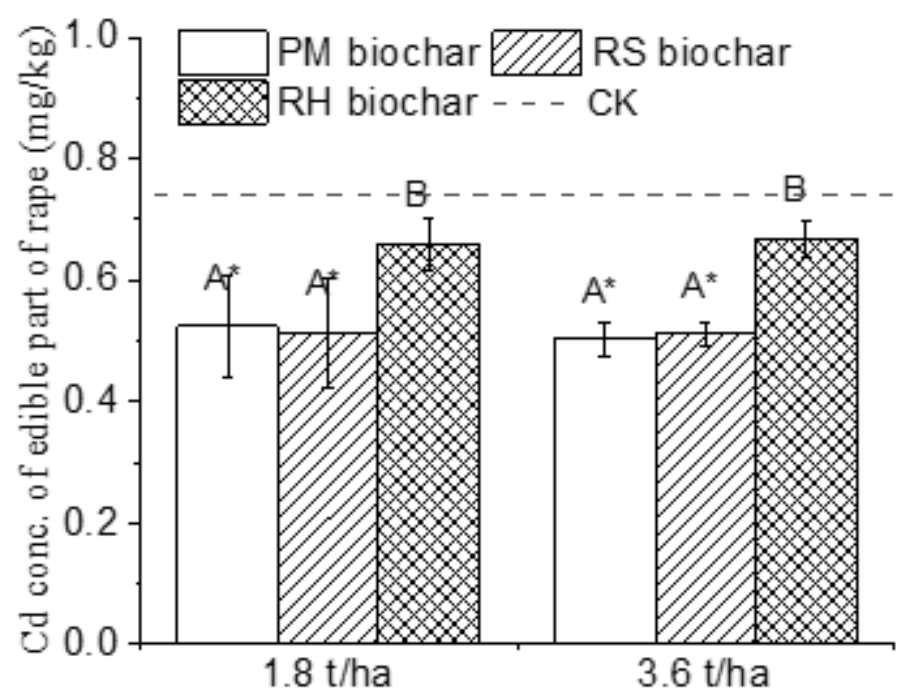

b)

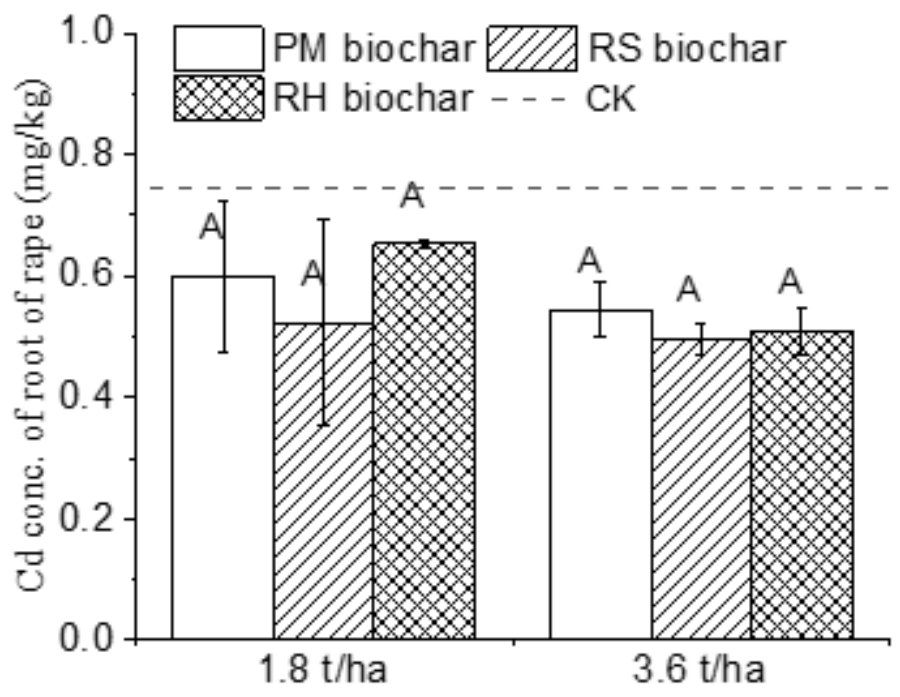

Figure 4

Cd concentrations in rape plants grown in soil and soil amended with biochars. "*" indicates a value to be significantly different to the control $(C K)$ value $(p<0.05)$. Like uppercase letters indicate no significant difference $(p>0.05)$ between groups with biochar amendment at like application rates.

\section{Supplementary Files}

This is a list of supplementary files associated with this preprint. Click to download.

- Graphicabstract.docx

- 202104Supplementarymaterials.docx 